\title{
UMA SEQUÊNCIA DIDÁTICA ENVOLVENDO A CONSTRUÇÃO DE UM TERRÁRIO NO ENSINO DE CONCEITOS DE ECOLOGIA
}

\author{
Gabriel Gonçalves Ribeiro Silva ${ }^{1}$
}

André Maciel da Silva ${ }^{2}$

Antônio Fernandes Nascimento Júnior ${ }^{3}$

\begin{abstract}
RESUMO
Várias são as atividades com o intuito de educar comunidades diversas no que tange a questão ambiental, no entanto, muitas vezes o assunto é tratado de maneira conservadora e superficial, principalmente em sala de aula, não estimulando o aluno a refletir sobre os problemas e seu papel na conservação do ambiente. $O$ presente trabalho descreve o desenvolvimento de uma estratégia didática para abordar temas ambientais no ensino fundamental II. Assim é apresentada uma sequência didática que contempla a construção de um terrário em uma sala de $7^{\circ}$ ano. Na primeira aula foi discutido com os alunos alguns conceitos básicos da ecologia e o terrário foi construído. $\mathrm{Na}$ segunda, foi realizada uma visita até a horta da escola e foram feitas comparações com o terrário. $\mathrm{Na}$ última aula, um vídeo foi utilizado para relembrar as discussões das últimas aulas e permitir um aprofundamento maior nas reflexões. Foi pedido aos alunos que avaliassem as aulas. Com base nestas avaliações, foi possível perceber que a prática foi eficiente não apenas para o ensino de conceitos formais, mas também para a formação cidadã dos discentes, que puderam se aperceber como agentes transformadores do ambiente.
\end{abstract}

PALAVRAS-CHAVE: Terrário. Educação Ambiental. Ensino de Ciências.

\section{A SEQUENCE TEACHING INVOLVING THE CONSTRUCTION OF A TERRARIUM IN ECOLOGY CONCEPTS OF EDUCATION}

\author{
ABSTRACT \\ There are many activities that intend to educate various communities on the subject of the \\ environmental question, but often the topic is treated in a conservatively and superficial way, \\ especially in the classroom, not encouraging students to reflect on the issues and their active role in \\ environmental conservation. Considering the need for an environmental education that permits the

\footnotetext{
${ }^{1}$ Licenciando em Ciências Biológicas, Universidade Federal de Lavras, MG. gabrielgrsilva@yahoo.com.br.

${ }^{2}$ Licenciando em Ciências Biológicas, Universidade Federal de Lavras, MG.

andremaciel_29@hotmail.com

${ }^{3}$ Professor Adjunto do Departamento de Biologia, Universidade Federal de Lavras, MG.

toni_nascimento@yahoo.com.br
} 
students to develop critical thinking about the nature, the role of society and themselves in relation to it, several authors have developed strategies that can be applied successfully in the classroom. This paper describes the development of a didatical strategy to approach environmental themes on fundamental teaching II. It is presented a didactic sequence which contemplates the construction of a terrarium in a 7th grade classroom for teaching environmental education and ecology concepts. In the first class, it was discussed with the students some basic concepts of ecology and the terrarium was built. On the second class, a visit was made to the school garden, and comparisons were made with the terrarium. In the last class, a video was used to recall the lessons of the latest discussions and allow further deepening the reflections. It was asked students to rate and give opinios about the lessons. Based on these assessments, it was revealed that the practice was efficient not only for teaching formal concepts, but also to civic education of the students, who were able to understand themselves as environmental change agents.

Keywords: Terrarium. Environmental Education. Science Teaching.

\title{
A SECUENCIA DIDÁCTICA INCLUYE LA CONSTRUCCIÓN DE UN TERRARIO EN CONCEPTOS ECOLOGÍA DE LA EDUCACIÓN
}

\begin{abstract}
RESUMEN
Hay varias actividades con el fin de educar a varias comunidades en materia ambiental, sin embargo, a menudo es tratada de forma conservadora y de manera superficial, sobre todo en el aula, no alienta a los estudiantes a reflexionar sobre los problemas y su papel en la conservación del medio ambiente. En este trabajo se describe el desarrollo de una estrategia educativa para abordar las cuestiones ambientales en la educación básica II. Por lo tanto presenta una secuencia didáctica que incluye la construcción de un terrario en un aula séptimo grado. La primera clase fue discutido con los estudiantes algunos conceptos básicos de la ecología y el terrario se construyó. El segundo se realizó una visita al jardín de la escuela y las comparaciones se hicieron con el terrario. En la última clase, se utilizó un video para recordar las lecciones de los últimos debates y permitir una mayor profundización de las reflexiones. Se preguntó a los estudiantes a evaluar las lecciones. Sobre la base de estas evaluaciones, se reveló que la práctica fue eficaz no sólo para la enseñanza de conceptos formales, sino también a la educación cívica de los estudiantes que fueron capaces de darse cuenta de cómo los agentes de cambio ambiental.
\end{abstract}

Palabras clave: Terrario. Educación Ambiental. Enseñanza de las Ciencias.

\section{Introdução}

Atualmente, há uma intensificação quanto às preocupações sobre o meio ambiente e sua conservação. Nota-se uma variedade de projetos e atividades em diversos setores da sociedade que objetivam educar as comunidades, sensibilizando-as para as diversas questões ambientais, de modo a tentar gerar posturas que minimizem ações destrutivas ao ambiente (SOARES; GURGEL, 2012).

A educação ambiental dentro da sala de aula, no entanto, é ainda tratada de maneira conservadora apoiada, por exemplo, na ideia muito comum de "cada um fazer sua parte", reduzindo as preocupações ambientais a ações pontuais como do descarte correto do lixo doméstico e da redução do uso da água. Tais ações têm sua 
importância e valor, mas, além disso, o professor deve preocupar-se em trazer para a sala de aula reflexões sobre os impactos ambientais em maior escala, como sobre o desmatamento causado na plantação de monoculturas e na poluição do ar por grandes indústrias, questões que possuem grandes implicações sociais, políticas e econômicas.

Essa visão crítica é importante para permitir ao aluno perceber-se como parte do ambiente e como agente transformador deste ambiente, e não como indivíduo distante destes problemas. Além de abrir caminho para que os alunos exerçam sua cidadania, pois assim podem reconhecer seus direitos e seus papéis na sociedade contemporânea (MELLO; TRAJBER, 2007; BRASIL, 1997 apud SILVA; CALIXTO, 2013).

Outro problema frequente nas escolas é a predominante utilização de estratégias expositivas que não estimulam o aluno a reflexão. Segundo Miranda et. al. (2010), atividades didáticas que desafiam os alunos, levando-os a refletir sobre situações cotidianas e se posicionarem como partes da natureza e da espécie humana, podem estimulá-los a perceber o significado dos saberes científicos para suas ações no dia-a-dia. Contudo, como afirmam Batista e Bizzeril (2013) as aulas sobre ecologia no Ensino Médio, por exemplo, em geral são realizadas de maneira tradicional, apenas com a exposição oral dos conteúdos, dispensando outras modalidades didáticas que poderiam enriquecer o estudo. Considerando estas preocupações, várias estratégias são desenvolvidas trazer discussões construtivas para a sala de aula.

Batista e Bizzeril (2013) argumentam sobre as diversas possibilidades que a utilização de um vídeo no $1^{\circ}$ ano do ensino médio fornece para o ensino de conceitos ecológicos no Ensino Médio. Os autores ressaltam que o vídeo é uma ferramenta de suporte, não devendo ser utilizado para simples substituição das aulas, o que é feito por muitos profissionais da educação,

Os Jogos educativos também são reconhecidos. Nascimento Júnior e Gonçalves (2013) utilizaram uma oficina pedagógica com jogos no ensino de ecologia e na educação ambiental. Dentre os jogos apresentados estavam jogos de montar ecológicos, trilha ecológica e dominó ecológico. Os autores apontam que este tipo de estratégia também favorece a motivação e as interações sociais dos participantes, além da aquisição de conceitos. 
Existem diversas outras estratégias que podem ser utilizadas, como livros (SILVA et al 2011), aulas de campo (OLIVEIRA;CORREIA, 2013) e brincadeiras (CARVALHO; MACEDO, 2008). Este trabalho tem a preocupação de trazer uma contribuição para o repertório e para a reflexão sobre estratégias didáticas no ensino de ecologia e de Educação Ambiental, assim será relatado o desenvolvimento de uma sequência didática utilizando-se de um terrário e de vídeos.

\section{Metodologia}

O público alvo da sequência didática foi uma sala de $7^{\circ}$ ano, realizada durante as aulas de ciências. Toda a atividade ocorreu durante uma disciplina de estágio do curso de Licenciatura em Ciências Biológicas da Universidade Federal de Lavras (UFLA), em uma escola pública do município de Lavras, conveniada com a universidade. $O$ desenvolvimento das atividades aconteceu em três momentos distintos.

\section{Primeiro momento: Construção das aulas}

Foi planejada uma sequência didática de três aulas. Na primeira aula, a proposta foi construir um terrário junto com os alunos, discutindo conceitos básicos sobre ecossistema e sua composição. Na segunda aula, levamos novamente o terrário para a sala de aula, e na sequência levamos os alunos até a horta da escola, comparando terrário e horta. Na terceira e última aula, utilizamos um vídeo a fim de incentivar os alunos a refletirem sobre a exploração descontrolada dos ecossistemas.

\section{Segundo momento: Ministração das aulas}

A primeira aula aconteceu no laboratório da escola facilitando a construção do terrário pelos alunos. Iniciou-se com uma breve apresentação oral dos conceitos sobre o ecossistema e seus componentes. Perguntou-se primeiramente aos alunos o que eram fatores bióticos e abióticos, resgatando seus conhecimentos prévios, e chegando juntamente com eles na conclusão que os fatores bióticos possuem vida e os abióticos não. Em seguida, foram construídas duas colunas no quadro da sala, 
uma para os fatores bióticos e outra para os abióticos. Foi perguntado então aos alunos se eles conheciam exemplos para cada um desses conceitos, e mencionaram alguns animais e plantas para a primeira coluna, e objetos como pedra, areia, água, etc. Todos estes exemplos foram colocados em suas respectivas colunas no quadro. Foi então dito então aos alunos que o ecossistema é o conjunto de todos esses itens, interagindo entre si. A construção do terrário foi proposta aos alunos, explicando a eles que ele se pode ser chamado de um microecossistema.

Para a construção do terrário foi utilizada uma camada de pedra, uma de areia e uma de terra, além de cobertura vegetal. A construção do terrário foi feita pelos alunos em um grande recipiente de vidro, com a ajuda e mediação dos estagiários, que forneceram o material necessário. Após a colocação destes componentes, os alunos colocaram um pouco de água no recipiente e fecharam o terrário com uma tampa de vidro, fixada ao terrário pelos estagiários com papel contact (figura 1).

Figura 1: O terrário produzido

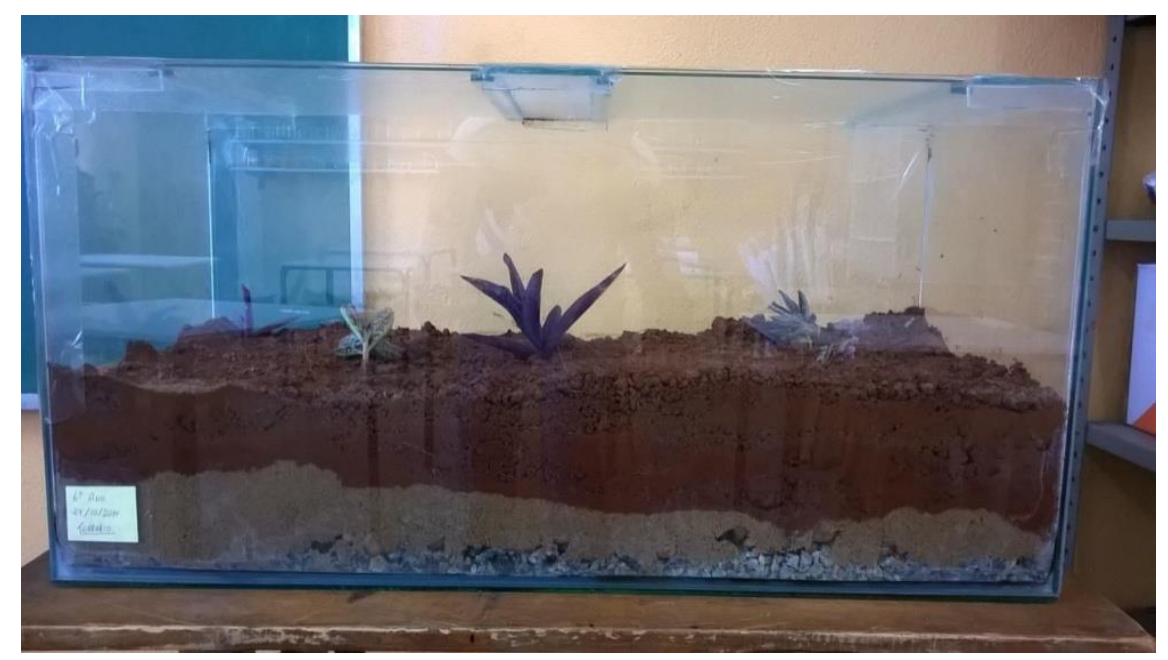

A segunda aula aconteceu após uma semana. Os alunos foram levados até a horta da escola juntamente com o terrário, a fim de fazer comparações entre ambos. Foi perguntado aos alunos se eles percebiam semelhanças entre o terrário e a horta, e alguns disseram que sim. Então, o estagiário perguntou quais eram estas semelhanças e, para auxiliá-los, lembrou a eles dos conceitos trabalhados na 
primeira aula, mencionando que os fatores bióticos e abióticos também estavam presentes na horta. Eles citaram os mesmos fatores presentes no terrário, listados na última aula, e perceberam alguns outros na horta, como passarinhos, minhoca, formiga, no caso dos fatores bióticos. Foi dito a eles, então, que a horta é semelhante ao terrário, porém em escala maior, e, logo, o terrário era uma representação em miniatura do que eles estavam vendo na horta.

Neste momento, foram lançadas diversas perguntas aos alunos, com o intuito de incentivá-los a refletir sobre o meio ambiente. As perguntas foram: "O que aconteceria se o ser humano alterasse o ambiente, por exemplo, retirando fatores bióticos e abióticos? Por que? Por exemplo, o que aconteceria se a extração de madeira para fazer papel fosse muito grande, ou seja, muita madeira fosse extraída? E no caso da caça, o que acontece se um animal for caçado de forma muito intensa?" . Analisando as respostas dos alunos a todas as questões feitas, pôde-se perceber que eles entenderam que a exploração predatória da natureza pode causar diversos problemas ao equilíbrio do ecossistema, pois os fatores bióticos e abióticos dependem uns dos outros.

A aula foi encerrada dizendo aos alunos que eles entenderiam tudo isso na próxima aula, onde eles veriam um vídeo sobre o assunto (figura 2).

Figura 2: A aula sendo ministrada na horta da escola

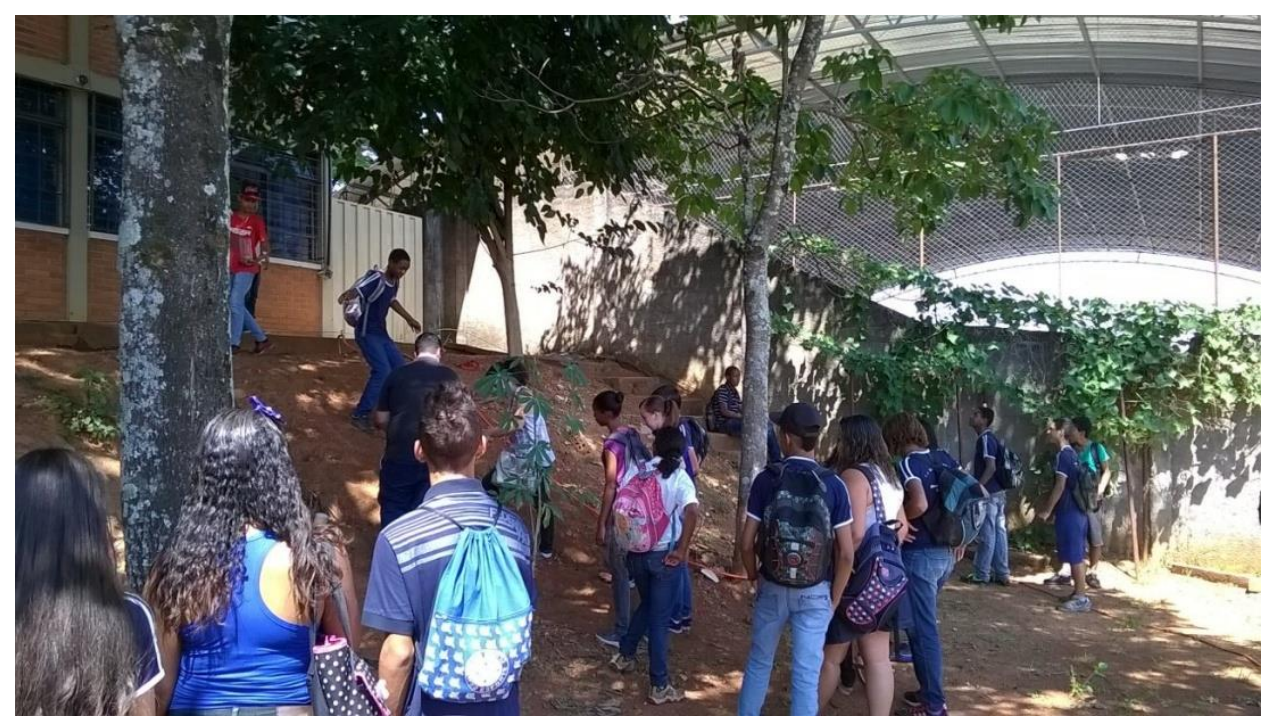

$\mathrm{Na}$ terceira aula, os alunos foram levados até a sala de vídeo da escola, e foi mostrado a eles o vídeo "A história das coisas". O vídeo fala sobre o processo de 
exploração dos ecossistemas, produção de materiais, consumo e descarte, e o porque isso é extremamente prejudicial não só para a natureza, mas também para os cidadãos, se feito da maneira como acontecesse atualmente, de forma predatória. Além disso, trata da questão do lixo e como ele muitas vezes é produzido em quantidade desnecessária e descartado de maneira inapropriada.

Após o vídeo, foi discutido com os alunos o que entenderam do vídeo. Os mesmos lembraram da aula anterior, onde haviam percebido a relação entre os diversos fatores bióticos e abióticos, e também disseram que o vídeo também mostra que todos estão sendo afetados pelo que acontece com a natureza. Foi então perguntado se isso acontece na cidade ou mesmo no próprio bairro onde vivem, e também se há muitas indústrias pela região que agem desta forma, e eles identificaram que há esses problemas pela região, sendo que alguns alunos disseram que tem membros da família que trabalham nestas grandes empresas. (Aqui, removi alguns dos "eles". Ficou bom assim?)

Ao final da aula, foi pedido que os alunos avaliassem as aulas, escrevendo em um pedaço de papel o que aprenderam com elas e o que mais gostaram ou não gostaram nestas três aulas.

Eis algumas das avaliações dos alunos. As avaliações foram entregues anonimamente:

P1: "Aprendi na aula que o meio ambiente é muito mais do que as florestas e os animais, mas tudo que tá perto da gente. A aula me mostrou que a gente tem que tomar mais cuidado com ele pra não acabar."

P2:“Adorei a Aula. Os professores mostraram no vídeo que muitas vezes é a gente mesmo que atrapalha a natureza."

P3:“Entendi o que é o meio ambiente. Aprendi também que devo tentar melhorar ele pra ele não acabar mais pra frente. Pra mim antes meio ambiente era só floresta agora sei que não."

P4:"Aprendi que todo lugar onde a gente vive chama meio ambiente e não só as florestas."

P5:“Eu aprendi que o desmatamento prejudica muito, e que deixar o lixo em qualquer lugar é ruim." 
P6:"Achei legal a aula pq me mostrou que eu já fiz muita coisa ruim pro meio ambiente e nem sabia. Sei que tem gente que faz muito mais, mas eu já fiz alguma coisa ruim. Vou cuidar melhor dele agora."

P7:“O que mais gostei na aula foi fazer várias coisas diferentes. Fiz terrários, fui na horta da escola e vi um vídeo. Gostei muito dos professores por isso, espero que eles voltem."

P8:“Gostei da aula pq foi diferente. Queria que os professores daqui fizessem essas aulas também."

P9:"Acho que o mais importante que eu aprendi foi que eu sou do ambiente também. Eu achava que tava separado dele, agora sei que não."

P10:"Achei muito legal os professores levarem a gente pra fora da sala pra estudar na horta da escola. Eles ainda fizeram um monte de coisa legal igual o terrario e o vídeo que a gente viu. Adorei vocês."

É possível perceber, por estas avaliações, que a prática possibilitou reflexões interessantes e relevantes para o processo de ensino-aprendizagem, não apenas para construir os conteúdos formais com os alunos, mas também para mostrá-los que eles também se inserem no mundo como agentes transformadores do mesmo, desse modo, carregando consigo a responsabilidade ambiental.

\section{DISCUSSÃo}

A proposta desta atividade foi contribuir não apenas para a construção formal do conteúdo previsto para os alunos, mas também para a formação cidadã dos discentes. Segundo Soares e Gurgel (2012), ao se trabalhar com o meio ambiente nas escolas, é necessário que se contribua com a formação de cidadãos capazes de decidir e atuar sobre a realidade socioambiental, preocupando-se com a vida e o bem-estar de todos, local e globalmente.

Embora o conhecimento sobre questões ambientais pareça, por vezes, trivial, já que podemos ver vários meios de comunicação sendo utilizados dentro e fora das escolas para tratar do tema, é essencial que o professor tenha conhecimento da importância e relevância que o assunto merece dentro da sala de aula. Embora o conhecimento de que as ações antrópicas vêm colocando em risco a vida no planeta 
seja relativamente popular atualmente, percebe-se que este saber não se efetivou em mudanças na postura humana para com a natureza (THOMAZ, 2006). Isso mostra que a simples divulgação dos problemas não basta, é necessário que o professor incentive os alunos a refletir sobre a situação ambiental atual, colocandoos como parte dos acontecimentos.

Silva e Calixto (2013) lembram que é esperado que o docente possa levar os alunos a compreender o espaço habitado por eles e a pensar em ações para a melhoria local.

São notadas as vantagens de uma atividade não convencional nas avaliações dos alunos sobre as aulas, pois não apenas percebe-se que conseguiram entender e refletir sobre o conteúdo, mas também gostaram da atividade pelo fato dela ser "diferente". Sobre isso, Oliveira et al (2014) mencionam a importância de se compartilhar informações sobre os problemas ambientais através de atividades lúdicas, no ensino de educação ambiental.

Dessa maneira, é possível perceber a importância de se compartilhar essas informações, principalmente através do desenvolvimento de atividades lúdicas para o ensino de educação ambiental,

\section{CONCLUSÃO}

A prática apresentada permitiu que os discentes refletissem um pouco mais sobre seu papel na sociedade contemporânea, e mostrando a eles que é necessário não apenas perceber o mundo como uns observadores passivos, mas sim, como agentes ativos e transformadores do meio em que vivem, contribuindo para sua formação cidadã pessoal. Além disso, a atividade auxiliou na compreensão dos conceitos formais de ecologia pelos alunos.

\section{REFERÊNCIAS BIBLIOGRÁFICAS}

BATISTA, M. B. O. ; BIZZERIL, M. X. A. ; O vídeo como ferramenta didática para o ensino de ecologia. 2013. Trabalho de Conclusão de Curso. (Graduação em Licenciatura em Ciências Naturais) - Universidade de Brasília.

BRASIL. Ministério de Educação. Parâmetros Curriculares Nacionais: terceiro e quarto ciclos: Temas Transversais. Secretaria de Ensino Fundamental. Brasília: MEC/SEF, 1998. 
da Alta Paulista

CALIXTO, Patricia. M. ; Lacerda, E. ; EDUCAÇÃO AMBIENTAL NA ESCOLA: curso de formação para professores. In: Mostra Nacional de Iniciação Científica e Tecnológica Interdisciplinar VI MICTI, 2013, Camboriú. VI Mostra de Iniciação Científica e Tecnológica Interdisciplinar, 2013.

CARVALHO, F. A. ; A biologia em obras infantis de Monteiro Lobato: modulações literárias, científicas e culturais. Ciência e Educação, v. 14, n.3, p. 467-482, 2008.

MIRANDA, A. C. B. ; JÓFILI, Z. M. S. ; CARNEIRO-LEÃO, A. M. A. ; Alfabetização Ecológica e formação de conceitos na educação infantil por meio de atividades lúdicas. Investigações em Ensino de Ciências (Online), 2010.

NASCIMENTO JÚNIOR, A. F. ; GONCALVES, L. V. ; Oficina de jogos pedagógicos de ensino de ecologia e educação ambiental como estratégia de ensino na formação de professores. Revista Práxis, v. 5, p. 71-75, 2013

OLIVEIRA, L. A. ; SILVA, A. M. ; NASCIMENTO JÚNIOR, Antonio Fernandes ; Oficina de reutilização de materiais: Educação ambiental crítica na formação de professores. Fórum Ambiental da Alta Paulista, v. 10, p. 46-57, 2014.

OLIVEIRA, A. P. L.; CORREIA, M. D. . Aula de campo como mecanismo facilitador do ensino aprendizagem sobre os ecossistemas recifais em alagoas. Alexandria (UFSC), v. 6, p. 163-190, 2013.

SOARES, M. C. A. ; GURGEL, B. S. ; Educação ambiental na escola. 2012. Trabalho de Conclusão de Curso. (Graduação em Ciências Biológicas - Licenciatura) - Universidade de Brasília.

SILVA, P. R.; CAVASSAN, O. ; CALDEIRA, A. M. de A. Macunaíma, o herói sem nenhum caráter: a obra de Mário de Andrade como recurso para o desenvolvimento de projetos de Educação Ambiental. In: V Encontro Regional Sul de Ensino de Biologia e IV Simpósio Latino Americano e Caribenho de Educação em Ciências, 2011, Londrina. Anais do V EREBIO-SUL e IV ICASE, 2011.

THOMAZ, C. E. ; CAMARGO, D. M. P. ; Educação Ambiental na Formação Inicial de Professores. In: V Congresso ibero-Americano de Educação Ambinetal, 2006, Joinville - SC. V Congresso iberoAmericano de Educação Ambiental. Joinville - SC, 2006. v. 1. p. 1-1 